\title{
Síndrome de Down: inclusão no atendimento odontológico municipal
}

\author{
Down Syndrome: The Inclusion in The Municipal Dental Service
}

\author{
Claudia Akemi Nacamura \\ Claudia Akemi Nacamura, José Carlos Yamashita, Rosana Modesto da Cunha Busch, Sara Nader Marta
}

José CARLos Yamashita

Cirurgião dentista, especialista em Endodontia, trabalha na Prefeitura Municipal de Bauru na unidade CEO (Centro de Especialidades Odontológicas - Bauru) na especialidade de endodontia.Professor Doutor da Universidade Sagrado

Coração - Bauru.

Cirurgiã dentista, especialista em Periodontia, trabalha na Prefeitura Municipal de Bauru na unidade CEO (Centro de Especialidades Odontológicas - Bauru) na especialidade de Periodontia.

\author{
Sara Nader Marta \\ Professora Doutora do Curso de Odontologia da Universidade Sagrado Coração - Bauru
}

\begin{abstract}
Resumo
A síndrome de Down (SD) é uma anomalia cromossômica. O indivíduo com esta síndrome apresenta alterações no sistema estomatognático: dentes, língua, periodonto, maxila, palato, mandíbula, oclusão e articulação temporomandibular. Há manifestações bucais, como respiração bucal, má oclusão, língua hipotônica, agenesias dentárias, doença periodontal, irrompimento dentário retardado, alterações de estrutura dentária e outras. Objetivo: o objetivo deste trabalho foi realizar um levantamento dos tratamentos realizados em diferentes especialidades nos pacientes com SD atendidos no Centro de Especialidades Odontológicas (CEO-Bauru). Material e Métodos: realizou-se um levantamento por meio de documentação indireta dos usuários do CEO-Bauru, da Prefeitura Municipal de Bauru, autorizado pelo Comitê de Ética da Universidade do Sagrado Coração de Bauru (n. 205/11). Foram selecionados 43 prontuários de pacientes atendidos no período de fevereiro de 2007 a janeiro de 2013. Resultados: os pacientes foram encaminhados ao CEO pelas Unidades Básicas de Saúde: 2,32\% Mary Dota, 2,32\% Geisel, 2,32\% Falcão, 4,65\% Santa Edwirges, 4,64\% Godoy, 9,30\% CEPS; e pelas escolas 2,32\% Emei Maria Elizabeth Pádua, 2,32\% Sorri e $72 \%$ Apae. Foram realizados 478 procedimentos preventivos e cirúrgico-restauradores sendo: $0,65 \%$ de curativos preventivos e cirúrgico-restauradores com a técnica de restauração atraumática (ART); 1,29\% de exodontias de decíduos e 5,38\% de permanentes; $7,53 \%$ de restaurações em decíduos e $15,70 \%$ em permanentes; $11,29 \%$ de raspagem supragengival, $6 \%$ de raspagem subgengival. Nos tratamentos curativos especializados: $0,43 \%$ de tratamentos endodônticos em dentes permanentes; $0,83 \%$ de raspagem periodontal. Dos tratamentos preventivos: 1,29\% de aplicação de verniz fluoretado, 9,24\% de selantes em permanentes e $38,06 \%$ de profilaxias. Conclusão: os cirurgiões-dentistas são os maiores promotores da saúde bucal, e conhecer as manifestações bucais da SD tem importância significativa. A inclusão dessa parcela da população para a realização de tratamento odontológico é possível e a procura por cuidados dentários tem sido cada vez maior, garantindo-lhes o direito à saúde prevista na Constituição. Palavras-chave: síndrome de Down; trisssomia; translocação; tratamento odontológico.
\end{abstract}

\begin{abstract}
Down syndrome (DS) is a chromosomal abnormality. The individual with this syndrome presents changes in the stomatognathic system: teeth, tongue, periodontal, maxilla, palate, jaw, occlusion, and TMJ. There are oral manifestations, such as mouth breathing, malocclusion, hypotonic tongue, dental agenesis, periodontal disease, delayed tooth eruption, tooth design changes and others. Objective: The objective of this study was to make a survey of the different kinds of treatment performed in DS patients at the Center for Dental Specialties (CEO - Bauru). Material and Methods: The authors conducted a survey through indirect documentation of CEO-Bauru users, authorized by the Ethics Committee of the University of the Sacred
\end{abstract}


Heart of Bauru (No. 205/11). We selected 43 medical records of patients seen from February 2007 to January 2013. Results: The patients were referred to the CEO by the Public Health Units: $2.32 \%$ from Mary Dota, 2.32\% from Geisel, $2.32 \%$ from Falcão, 4.65\% from Santa Edwirges, $4.64 \%$ from Godoy, 9.30\% from CEPS; and by schools: $2.32 \%$ from Emei Maria Elizabeth Padua, 2.32\% from Sorri, and $72 \%$ from Apae. Four hundred and seventy eight preventive and surgical-restorative procedures were conducted: preventive and surgical-restorative treatments with a-traumatic restoration technique (ART) $(0.65 \%)$; extraction of deciduous $(1.29 \%)$ and of permanent teeth $(5.38 \%)$; restoration of deciduous $(7.53 \%)$ and permanent teeth $(15.70 \%)$; supragingival scaling (11.29\%), and subgingival scaling (6\%.) In specialized curative treatments there were endodontic treatments in permanent teeth $(0.43 \%)$; periodontal scaling $(0.83 \%)$. Preventive treatments: application of fluoride varnish $(1.29 \%)$, sealants in permanent teeth $(9.24 \%)$ and prophylaxis $(38.06 \%)$. Conclusion: dentists are the greatest promoters of oral health, and knowing DS's oral manifestations is of significant importance. The inclusion of this segment of the population in public dental treatment is possible and the demand for dental care has been growing, guaranteeing them their right to health which is provided for by the Constitution.

Keywords: Down syndrome, trissomy, translocation ; dental treatment.

\section{INTRODUÇÃO}

A síndrome de Down (SD) é uma anomalia cromossômica, caracterizada por uma série de sinais e sintomas, ${ }^{1,2}$ denominada trissomia simples do cromossomo 21., 1,2,3 Constitui uma das principais causas de deficiência mental de origem pré-natal e é considerada a anomalia mental congênita mais comum. ${ }^{1,4,5}$ Foi a primeira síndrome de malformação cromossômica encontrada no homem, ${ }^{5,6}$ sendo a mais prevalente delas. ${ }^{6,7,8}$ Sua incidência é de aproximadamente 1 para 600 a 800 nascimentos com vida. ${ }^{1,2,3,4,5,7,7,9,10}$ Também é conhecida como mongolismo, trissomia do cromossomo 21 , ou síndrome da trissomia G. $1,7,8,10$

A palavra inclusão tem como significa possibilitar à pessoa com deficiência iguais possibilidades de cuidados no tratamento convencional e no diferenciado, nos quais pessoas com e sem deficiência possam conviver e serem tratadas; os profissionais devem aprender a lidar com as diversidades e diferenças..$^{1,5}$

O quadro clínico da SD foi descrita pela primeira vez em 1866, pelo médico inglês John Langdom Hayden Down. ${ }^{1,2,5,7,8,11,12}$ No artigo "Observation on classification of idiots", 7 observou o aspecto oblíquo dos olhos dos afetados e considerou-os um retrocesso da evolução, nomeando essa condição "idiotia mongoliana" em razão das semelhanças físicas dos indivíduos afetados com as das pessoas da raça mongólica. Daí provêm os termos mongolismo e mongoloides. ${ }^{1,2,4,7} \mathrm{~A}$ nomenclatura atualmente utilizada é trissomia do cromossomo 21, ou apenas síndrome de Down, em homenagem ao primeiro descritor. ${ }^{6}$ A denominação síndrome da trissomia $G$ devese ao cromossomo extra estar no grupo G. ${ }^{6,12}$

A razão pela qual essa desfiguração cromossômica ocorre ainda é questionável. ${ }^{6}$ Fatores como idade materna avançada (com 40 anos ou mais) durante a gravidez ou a tendência familiar à não disjunção cromossômica têm sido especulados como eventuais causas. $6,7,12$ Também há estudos recentes que mostram que a idade paterna influencia a aneuploidia. ${ }^{10}$ Fatores extrínsecos, como radiações, drogas e vírus possuem particular importância nas alterações, uma vez que induzem a quebras cromossômicas. ${ }^{6}$

A definição etiológica é complicada pela identificação de três tipos de aberrações cromossômicas detectadas por um exame cromossômico: trissomia do 21 simples ou padrão (95\%), translocação (3\%) e mosaicismo $(2 \%), 6,7,12$

Os indivíduos com esta síndrome apresentam senilidade prematura, ${ }^{6,7}$ alta taxa de mortalidade, ${ }^{10}$ expectativa de vida reduzida, risco de leucemia aguda e óbitos 
por doenças respiratórias ou cardíacas. ${ }^{1,7,8}$ O aumento na sobrevida, hoje, deve-se à melhora no atendimento clínico-cirúrgico das crianças, ${ }^{3}$ levando à necessidade de maior integração na sociedade. ${ }^{11}$ Ressalta-se a importância da colaboração familiar e de uma equipe multidisciplinar no tratamento destes pacientes. ${ }^{2,5}$

O diagnóstico da SD é estabelecido com base em sinais e sintomas e, posteriormente, confirmado pelo estudo cromossômico para identificar o cariótipo. $^{2,5}$ As características gerais dos portadores desta síndrome são: ausência do reflexo de Moro, hipotonia muscular generalizada, baixa estatura, face achatada, braquicefalia (cabeça larga e curta), pescoço largo e curto com pele redundante na nuca, fenda palpebral oblíqua, orelhas displásicas e com implantação baixa, prega palmar transversa única (prega simiesca), encurtamento das extremidades (mãos, pés, dedos, nariz e orelhas), clinodactilia (encurtamento da falange média), nariz em sela, envelhecimento precoce, bochechas salientes, pés com amplo espaço entre o primeiro e segundo dedos com um sulco estendendo-se próximo à face plantar, cabelo fino e esparso. ${ }^{1,2,4,7,12}$

Dentre as manifestações sistêmica na SD estão: quociente de inteligência reduzido; cardiopatia congênita $(40 \%$ a $50 \%)$; audição diminuída (70\% a $80 \%)$; problemas oftálmicos; sistema imunológico debilitado; hipotonia muscular esquelética; anomalias gastrintestinais, hematológicas, dermatológicas, respiratórias, na fertilidade e neurológicas; hipotireoidismo; alteração na coordenação motora e envelhecimento precoce. . $^{2,5,7,12}$

O paciente com SD apresenta alterações no sistema estomatognático: dentes, língua, periodonto, maxila, palato, mandíbula, oclusão e articulação temporomandibular. Há manifestações bucais, dentre elas: respiração bucal, maxila atrésica, língua fissurada, língua hipotônica, macroglossia, agenesias dentárias, doença periodontal, irrompimento dentário retardado, maloclusão, alterações de estrutura dentária, candidíase e úvula bífida. ${ }^{2,3,6,10} \mathrm{O}$ cirurgião dentista precisa conhecer estas alterações bucais para executar com êxito um atendimento de qualidade. .,4,5 $^{2}$

Em relação à língua, a literatura é controversa. Uma linha de pesquisadores acredita que os portadores da SD apresentam macroglossia e outra linha diz que a língua tem tamanho normal, contudo, a cavidade bucal apresenta-se com tamanho reduzido em razão do hipodesenvolvimento do terço médio da face, ocasionando desconforto para o alojamento da língua no interior da cavidade bucal. Assim, a língua é posicionada entre os lábios, protraindo-a, dando a ilusão de língua aumentada (macroglossia relativa). ${ }^{1,12,13}$ Alguns acreditam que o aumento volumétrico da língua aparece em decorrência de uma musculatura mais flácida (hipotonia muscular), e não em virtude de um aumento de sua massa muscular. ${ }^{1}$ A macroglossia provoca deslocamento dos dentes e, consequentemente, má oclusão e hábitos bucais deletérios (respiração bucal). ${ }^{1,2,3,12}$ Como consequência da macroglossia e da hipotonicidade da língua, os lábios apresentam-se frequentemente banhados por saliva, levando à irritação e fissura dos cantos labiais, queilite angular, facilitando a instalação de processos infecciosos (candidíase). ${ }^{2,9,12} \mathrm{~A}$ hipotonia muscular dificulta a fala, a mastigação (formação do bolo alimentar), a deglutição e a sucção. ${ }^{2}$ A presença do palato estreito e curto e a hipotonia facial extra e intraoral contribuem para uma oclusão labial pobre, sucção fraca, pouco controle dos movimentos da língua e dificuldades com a mandíbula, podendo resultar em déficit nas habilidades motoras $\mathrm{e}$ orais. ${ }^{5,14}$ Há, também, a presença de língua fissurada, propiciando a retenção de bactérias 
e restos alimentares que causam halitose..$^{1,2,5}$

Em virtude do hipodesenvolvimento do terço médio da face, há presença de pseudoprognatismo, assim como palato duro menor e ogival, ${ }^{4,12}$ sendo reduzido em altura e comprimento. $^{3} \mathrm{O}$ hipodesenvolvimento da maxila e do palato em relação ao desenvolvimento da mandíbula (que tem um crescimento normal) ocasiona encurtamento da arcada superior, gerando apinhamento dental. ${ }^{5}$ Acredita-se que a micrognatia do maxilar seja a responsável pela protrusão da língua. ${ }^{5}$ Com a maxila proporcionalmente menor, ocorre a mordida cruzada posterior. A língua dos portadores desta síndrome protrai os dentes anteriores, levando à mordida aberta anterior. ${ }^{5,12}$ A mandíbula pode se apresentar expandida transversalmente em razão de pressões linguais. ${ }^{2}$ A oclusão tipo III de Angle é frequente nesta síndrome, com a presença de mordida cruzada. ${ }^{2,5,12}$

O bruxismo é uma manifestação comum na SD e causador da ação de força excessiva na articulação temporomandibular, provocando distensão muscular e levando a sintomatologia dolorosa e problemas periodontais. ${ }^{2,5}$ Alguns autores atribuem-na à morfologia com poucas fóssulas e fissuras e superfícies oclusais mais planas por causa do bruxismo. .,8 $^{5}$

O portador da SD apresenta uma série de alterações que comprometem sua qualidade vida, dentre elas a doença periodontal que se mostra precoce, severa e de progressão rápida. ${ }^{1,6,7,8} \quad \mathrm{~A}$ deficiência imunológica provavelmente seja o fator de maior contribuição para a evolução das doenças periodontais, uma vez que o organismo exibe dificuldades em combater as bactérias que estão no biofilme dental, ${ }^{4,6,7}$ fazendo com que a doença periodontal seja mais agressiva nesses pacientes..$^{2,5,7}$ As deficiências motoras $^{5}$ e neurológicas, juntamente com a hipotonia muscular, diminuição da capilaridade da mucosa e a má oclusão, dificultam a higienização bucal desses pacientes, tornandoos mais susceptíveis à doença periodontal, ${ }^{3}$ cuja prevalência é alta em adolescentes (30\% a $40 \%$ ) e atinge $100 \%$ dos indivíduos próximos

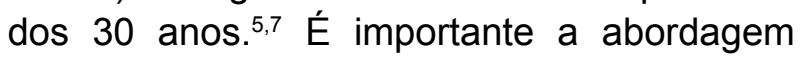
preventiva envolvendo e orientando o paciente, pais e educadores, objetivando uma melhor condição de saúde bucal. $., 5,6,9,11,15,16$

Há alta incidência de agenesia na SD, 2,13 alcançando $63 \%$ dos portadores. ${ }^{17}$ Acomete ambos os sexos, sendo comum na dentição permanente a ausência de terceiros molares, segundo pré-molares e incisivos laterais superiores e inferiores; na dentição decídua são mais afetados os incisivos laterais superiores e inferiores. A etiologia é desconhecida, sugerindo que as síndromes que causam a trissomia (não somente do 21) induzem a agenesia dental. ${ }^{13}$

Cerca de $50 \%$ a $73 \%$ dos portadores da SD exibem anomalias dentárias. , 8,17 Podem ser observadas hipodontia (ou oligodontia), dentes conoides (principalmente incisivos e caninos), microdentes, taurodontia, hipocalcificação de esmalte, fusão e geminação. Também pode ser observado o aumento da coroa de molares e inclinação da oclusal para lingual, o que pode dificultar o acesso em procedimentos restauradores. ${ }^{4,5,12,15,16}$ As raízes dos dentes são mais curtas, levando a proporções menores entre coroa e raiz. ${ }^{1,5}$

Mesmo apresentando a mineralização completa, os dentes dos portadores da SD podem sofrer alteração na sequência de erupção e atraso na erupção nas dentições decídua e permanente. . $^{2,8,12,17}$ Há relatos de que este atraso pode estar ligado a doenças sistêmicas, como hipotireoidismo e raquitismo, ou a um fator local, como a hiperplasia gengival. ${ }^{17} \mathrm{~A}$ erupção do primeiro dente decíduo na cavidade bucal ocorre por volta do $12^{\circ}$ ao $20^{\circ}$ mês de vida e estará completa por volta dos 4 aos 5 anos. ${ }^{2,10}$ Alguns decíduos podem ficar retidos até os 14 ou 15 anos de 
idade. ${ }^{10} \mathrm{Na}$ dentição permanente, o primeiro irrompimento ocorrerá por volta dos 8 ou 9 anos de idade. ${ }^{17}$

A maioria dos estudos relata um menor índice de cárie que na população não portadora desta síndrome, ${ }^{2,4,13}$ porém não se conseguiu explicar esse fato. Há uma teoria que diz que o índice de cáries é reduzido em razão das agenesias, que aumentam os espaços interproximais, dificultando a retenção de alimentos. ${ }^{4,5}$ Segundo outra teoria, na erupção tardia os dentes ficariam menos tempo expostos ao ataque ácido produzido pelas bactérias. ${ }^{4,5,8} \mathrm{~A}$ pequena presença de fóssulas e fissuras e as superfícies oclusais planas (consequência do bruxismo), em outra hipótese, também podem ser responsáveis pelo baixo índice de cáries. ${ }^{5,8,12}$ Há também relatos de que a prevalência reduzida de cárie em crianças com a SD talvez se deva ao menor número de Streptococcus mutans na saliva e maior $\mathrm{pH}$ salivar. ${ }^{7}$ Para alguns autores existe maior concentração de íons sódio, cloro e bicarbonato na composição salivar, sugerindo, por causa do aumento do íon bicarbonato, maior eficácia da capacidade tampão da saliva por meio do sistema carbonato-bicarbonato ${ }^{3,5,12}$ em relação à concentração e ao volume de ácido produzido pelas bactérias. ${ }^{3,5}$

Nas crianças com SD, além das alterações anátomo-fisiológicas bucais já descritas, há constantes doenças respiratórias e comprometimento simultâneo da resposta imunológica inata e adquirida, que fazem com que estes fatores adicionais tornem-nas mais suscetíveis a processos infecciosos, inclusive fúngicos, nos quais as espécies de cândida são os agentes etiológicos mais preponderantes. ${ }^{2}$ A candidíase pseudomembranosa é o quadro clínico fúngico mais detectável em crianças com essa cromossomopatia. ${ }^{18}$

De $40 \%$ a $60 \%$ dos portadores da SD apresentam algum tipo de cardiopatia, sendo as mais comuns o defeito completo do canal atrioventricular, defeito do septo ventricular e tetralogia de Fallot. ${ }^{19} \mathrm{~A}$ profilaxia antibiótica, como forma de prevenção da bacteremia transitória em pacientes suscetíveis à endocardite, tornou-se conduta racional na execução de procedimentos odontológicos. ${ }^{20}$ Dentre os procedimentos em que há sangramento e manipulação gengival estão as exodontias, procedimentos periodontais e raspagens. ${ }^{13,19} \mathrm{O}$ protocolo atual de profilaxia da endocardite bacteriana recomendada pela American Heart Association é a administração de $2 \mathrm{~g}$ de amoxicilina, em dose única, uma hora antes do procedimento em adultos, e, em crianças, $50 \mathrm{mg} / \mathrm{kg}$, uma hora antes do procedimento. Como antibiótico alternativo, via oral, para crianças, podem ser utilizadas a claritromicina ou a azitromicina em dose única de $15 \mathrm{mg} / \mathrm{kg}$, uma hora antes do procedimento..$^{20,21}$ Para adultos, as alternativas são a clindamicina (600 mg) ou a azitromicina (de 500 mg), também em dose única, uma hora antes do procedimento. Em pacientes incapazes de utilizar medicação via oral é recomendada a ampicilina ( $2 \mathrm{~g}$, e, para crianças, $50 \mathrm{mg} / \mathrm{kg}$ ) por via intramuscular ou endovenosa, trinta minutos antes do procedimento, e, em paciente com histórico de alergia, utiliza-se a clindamicina (600mg, e, para crianças, $20 \mathrm{mg} / \mathrm{kg}$ ). ${ }^{20}$

\section{Objetivo}

O objetivo deste trabalho foi realizar um levantamento dos tratamentos realizados em diferentes especialidades nos pacientes com SD atendidos no Centro de Especialidades Odontológicas (CEO-Bauru), demonstrar a possibilidade de sua inclusão no serviço odontológico do município de Bauru e no atendimento multidisciplinar, buscar as manifestações bucais nestes pacientes de acordo com o relatado na literatura.

\section{MATERIAIS E MÉtodos}

Realizou-se um estudo por meio de documentação direta e indireta dos usuários 
do CEO-Bauru, da Prefeitura Municipal de Bauru (PMB), autorizado pelo Comitê da Universidade do Sagrado Coração de Bauru (protocolo $n^{\circ}$ 205/2011). Foram selecionados 43 prontuários de portadores da SD no período de fevereiro de 2007 a janeiro de 2013.

Nos prontuários odontológicos, os pais ou responsáveis legais assinaram um termo de consentimento para a realização do tratamento odontológico e utilização do material para fins didáticos e científicos, e também para utilização de fotos e radiografias.

Foi realizado um estudo das características gerais e bucais dos portadores da SD, necessidade de tratamento odontológico e procedimentos odontológicos que foram possíveis de serem realizados em consultório odontológico, sem deixar de levar em consideração as condições de saúde geral do paciente, medicações de rotina e histórico do paciente.

Os pacientes foram encaminhados ao CEO pelas Unidades Básicas de Saúde (UBS) e escolas, por meio de agendamento na Central de Regulação do município. Das UBS, 2,32\% vieram do Mary Dota, 2,32\% do Geisel, 2,32\% da Falcão, 4,65\% da Santa Edwirges, 9,30\% da CEPS, 4,64\% do Godoy; das escolas, 2,32\% vieram da Escola Municipal de Educação Infantil (Emei) Maria Elizabeth Padua, 2,32\%, da Sorri, e 72\%, da Associação de Pais e Amigos dos Excepcionais (Apae).

\section{Resultados}

Nas manifestações bucais, observou-se, em concordância com os relatos da literatura, a presença de hipotonia muscular da língua, língua fissurada, maxila atrésica, doença periodontal grave em pacientes jovens, além da presença de gengivite marginal inicial, muitos pacientes livres de cárie, presença de dentes conoides, microdentes, agenesias de incisivos laterais, pré-molares na dentição, terceiros molares na dentição permanente e de incisivo lateral na decídua, retenção de molar decíduo, bruxismo, respiração bucal e queilite angular. Úvula bífida, taurodontismo, fusão ou geminação e infecção por cândida não foram encontrados na amostra estudada.

Os tratamentos odontológicos ambulatoriais realizados somaram 478 procedimentos advindos das unidades básicas, da Emei, Sorri e Apae (Gráfico 1).

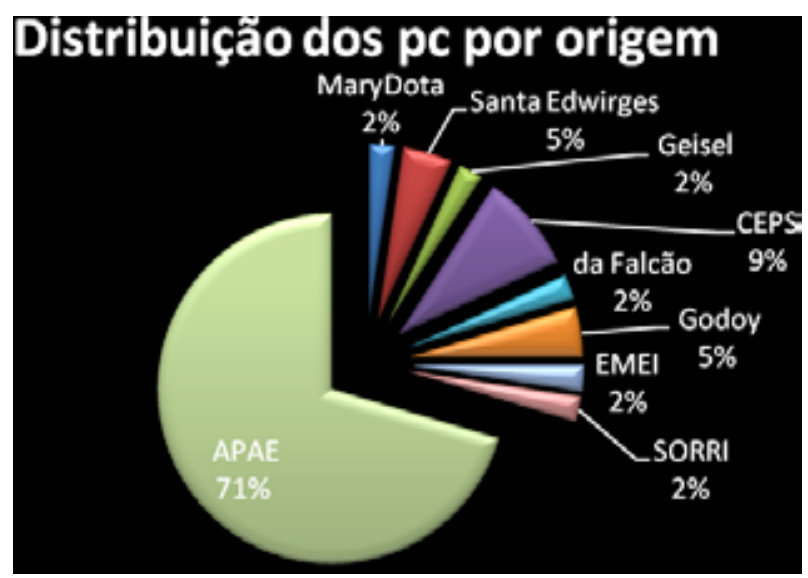

Gráfico 1 - Distribuição dos pacientes por locais de origem das Unidades Básicas.

As modalidades de tratamento foram: em $0,65 \%$, iniciou-se com a atraumatic restoration technique (ART); em 1,29\%, exodontias de decíduos; $5,38 \%$, exodontias de permanentes; em $7,53 \%$, restaurações em dentes decíduos; $15,70 \%$, restaurações em dentes permanentes; $11,29 \%$, raspagem periodontal supragengival; $5,57 \%$, raspagem subgengival; $0,43 \%$, raspagem subgengival ultrassônica. Nos tratamentos curativos especializados, $0,43 \%$ foram tratamentos endodônticos em dentes permanentes; 0,42\%, raspagem supragengival; e $0,41 \%$, raspagem subgengival manual e ultrassônica. Dentre os tratamentos preventivos, 9,24\% receberam aplicação de selantes em dentes permanentes; $1,29 \%$, aplicação de verniz fluoretado; $30,32 \%$, profilaxias com baixa rotação; $7,74 \%$, profilaxias com jato de bicarbonato (Gráfico 2). 


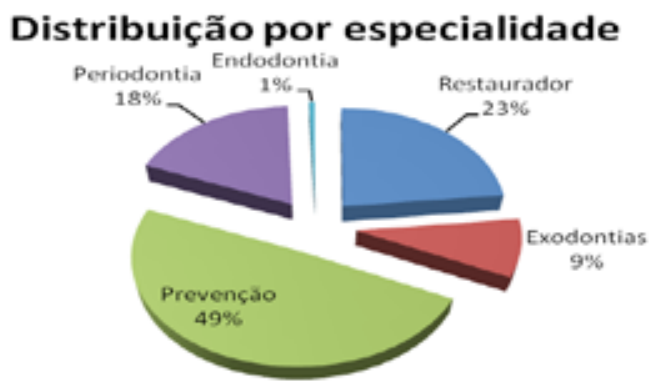

Gráfico 2 - Distribuição dos tratamentos realizados, por especialidade

Os pacientes foram receptivos a mais de um profissional, o que mostra a possibilidade do tratamento integrado. O único caso em que não foi possível realizar um tratamento preventivo foi em uma paciente para a qual se indicou a exodontia geral em razão de problema periodontal avançado. Nos tratamentos endodônticos, um dos casos deveu-se a trauma e o outro, a cárie extensa, sendo, neste caso, utilizado o Estabilizador de Godoy, na intenção de que a paciente não levasse a mão à cavidade bucal.

\section{Discussão}

No atendimento da pessoa com deficiência, nada é exato ou pré-definido; sempre nos deparamos com variações de paciente para paciente, mesmo dentro de uma mesma patologia. ${ }^{22}$

Os portadores de SD, assim como os demais pacientes com deficiência, apresentam certa dificuldade em encontrar o tratamento odontológico em virtude dos poucos profissionais interessados em suprir suas necessidades, sendo que muitos se sentem despreparados para esse tipo de atendimento. ${ }^{1,4,5,11,12,23}$

Muitas pessoas com deficiência apresentam dificuldade em manter boa saúde bucal ou ter acesso aos serviços odontológicos por alguma incapacidade ou condição médica. ${ }^{11}$

Os problemas odontológicos são frequentes nas pessoas com deficiência. Há alta incidência de cárie e gengivite pela dificuldade em manter a higiene bucal adequada, e outros fatores somam-se a este, como a respiração bucal, dieta cariogênica e anomalias de oclusão. 11,22 O grau de deficiência regula, em parte, a adaptação ou condicionamento do paciente aos cuidados odontológicos. Todos os tratamentos dos pacientes, desde os colaboradores até o que não oferece qualquer possibilidade de cooperação (indicado para anestesia geral), devem ser feitos dentro de uma prática preventiva. ${ }^{5,22,24} \mathrm{O}$ esforço do paciente e seu responsável, a motivação do dentista e um programa preventivo de saúde bucal são fatores relevantes para o sucesso de prevenção de doenças bucais nos portadores da SD. ${ }^{25}$

Ao tratar um paciente portador da SD, o cirurgião-dentista deve ficar atento às suas limitações e conhecer os diferenciais que ele apresenta. $^{12}$

\section{Conclusão}

As alterações bucais encontradas nos pacientes com SD atendidos e tratados foram: hipotonia muscular da língua, língua fissurada, maxila atrésica, doença periodontal; dentes conoides, microdentes, agenesias de incisivos laterais, pré-molares e teceiros molares na dentição permanente e de incisivo lateral na decídua, retenção de molar decíduo, bruxismo, respiração bucal e queilite angular.

Os tratamentos realizados envolveram 478 procedimentos, que incluíram as seguintes áreas, em ordem decrescente: prevenção, tratamentos restauradores, tratamentos periodontais, avulsões e endodontias.

É possível oferecer um tratamento odontológico integrado aos pacientes com SD. No CEO-Bauru, esses indivíduos foram provenientes da APAE, das Unidades Básicas de Saúde e escolas do município, demonstrando sua inclusão na sociedade. $O$ trabalho de prevenção é fundamental e deve ser realizado continuamente. 


\section{REFERÊNCIAS}

1. Aguiar SMHCA, Figliolia SLC, Puerro M, Fedalto MF. Características clínicas da língua de portadores da síndrome de Down. Rev Odontol Unesp. 2002; 23(1): 24-7.

2. Carvalho ACA, Campos PSF, Rebello IC. Síndrome de Down: aspectos relacionados ao sistema estomatognático. R Ci med biol. 2010; 9(supl.1): 49-52.

3. Ensslin AP, Langlois CO, Weigert KL, Silva ERA, Simioni FS. Parâmetros salivares e dentários de indivíduos portadores de síndrome de Down em um município do Rio Grande do Sul. Stomatos. 2009; 15(28): 58-66.

4. Gonçalves SS, Canalli CSE, Babinski SG, Babinski JW, Miasato JM. Levantamento das condições de cárie e doença periodontal na associação de portadores da Síndrome de Down em Teresópolis (RJ). Rev Odontol Univ Cid São Paulo. 2010; 2(1): 19-24.

5. Oliveira AC, Luz CLF, Paiva SM. O papel da saúde bucal na qualidade de vida do indivíduo com síndrome de Down. Arq Odontol. 2007; 43(4):162-8.

6. Alves RD, Silveira EJD, Lins RAU. Doença periodontal x síndrome de Down: uma revisão. Rev Fac Odontol da Ufgo. 1997; 1(1); 55-60.

7. Cavalcante LB, Pires JR, Caminaga RMS. Doença periodontal em indivíduos com síndrome de Down: enfoque genético. RGO. 2009; 57(4): 449-53.

8. Moraes MWL, Bastos MS, Moraes LC, Rocha JC. Prevalência de cárie pelo índice CPO-D em portadores de síndrome de Down. Pós-Grad Rev Odontol. 2002; 5(2): 64-73.

9. Ribeiro EL, Campos CC, Cardoso CG, Ferreira WM, Pimenta FC, Toledo AO. Candida albicans bucais de crianças com síndrome de Down: comportamento de tubos germinativos, exoenzimas e sensibilidade a toxinas "killer". Revista Odonto Ciência. 2007; 229570: 243-9.

10. Silva KG, Aguiar SMHCA. Erupção dental de crianças portadoras da síndrome de Down e crianças fenotipicamente normais: estudo comparativo. Rev Odontol Araçatuba. 2003; 24(1): 33-9.

11. Castro AM, Marchesoti MGN, Oliveira FS, Novaes MSP. Avaliação do tratamento odontoló- gico de pacientes com necessidades especiais sob anestesia geral. Rev Odont Unesp. 2010; 39(3): 137-2.

12. Santangelo CN, Gomes DP, Vilela LO, Deus TS, Santos EM. Avaliação das características bucais de pacientes portadores de síndrome de Down da Apae de Mogi das Cruzes (SP). ConScientae Saúde. 2008; 7(1): 29-4.

13. Fourniol Filho A. Pacientes especiais e a odontologia. São Paulo: Santos; 1998. Capítulo VI, Genética e sindromologia, $3{ }^{a}$ parte; p. 270-4.

14. Oliveira AC, Czeresnia D, Paiva SM, Campos MR, Ferreira EF, Uso de serviços odontológicos por pacientes com síndrome de Down. Rev Saúde Publ. 2008; 2(4): 693-9

15. Altun C, Guven G, Akgun OM, Akkurt MD, Basak F, Akbulut E, Oral Health Status of Disabled Individuals Attending Special Schools. Eur J Dent. 2010;, 4(4): 361-6.

16. Keinan D, Radko A, Smith P, Zilmerman U, Acid resistance of the enamel in primary second molars from childen with Down syndrome and cerebral palsy. Open Dent J. 2009; 3: 132-6.

17. Santos MJP, Sangalli J, Ferreira ACRM, Silva VC, Aguiar SMHCA, Incidência e características bucais de gêmeos monozigóticos, portadores da síndrome de Down, considerando os fatores ambiental e comportamental. Revista Odontológica de Araçatuba, 2009; 30(2): 57-2.

18. Vieira JDGV, Ribeiro EL, Campos CC, et al. Candida albicans isoladas da cavidade bucal de crianças com síndrome de Down: ocorrência e inibição do crescimento por Streptomyces sp. Rev Soc Bras Med Trop. 2005; 38(5): 383-6.

19. Noguti J, Frascino AVM, Lascane NA, Fraga CTP, Uso de profilaxia antibiótica para pacientes portadores de síndrome de Down. Rev Cir Traumatol Buco-Maxilo-Fac. 2010; 10(4): 31-7.

20. Branco FP, Volpato MC, Andrade ED, Profilaxia da endocardite bacteriana na clínica odontológica: o que mudou nos últimos anos. Rev $\mathrm{Pe}-$ riod. 2007; 17(03): 23-8.

21. Carmo ED, Amadei SU, Pereira AC, Silviera VAS, Rosa LEB, Prescrição medicamentosa em odontopediatria. Rev Odontol Unesp. 2009; 38(4): 256-62. 
22. Haddad AS, et al. Odontologia para pacientes com necessidades especiais São Paulo: Santos; 2007. Capítulo 17, parte II; p 206.

23. Varellis MLZ. Método de estabilização do paciente com distúrbio neuromotor, Rev Gaucha Odont. out.-dez. 2002; 50(4): 209-216.

24. Abreu KCS, Franco SOB, Calheiros PR. Abordagem odontológica para pacientes portadores de distúrbios neuropsicomotores. [Trabalho de Conclusão de Curso]. Conselheiro Lafaiete: Fa- culdade de Medicina da Universidade Federal de Minas Gerais.; 2012.

25. Castilho ARF, Marta SN. Avaliação da incidência de cárie em pacientes com síndrome de Down após sua inserção em um programa preventivo. Ciência \& Saúde Coletiva. out. 2010; 15(supl 2): 3249-53.

Submetido em: 25-3-2015

Aceito em: 14-5-2015 